this way. These authors also state that B. tetrni liquefies gelatin, which does not occur with our organism.

Differences in colonies, though never of any great value, are well marked between the two organisms. The wavy out line of the $B$. tetani colonies is not seen, nor does our organism produce the branching and rounded processes in streak cultures. The branches we have described as "dendritic" are not characteristic, and when produced are fine and thread-like and almost completely transparent.

Finally, a very marked difference between the two is the apparently complete absence of toxin production.

conolusions. - We regard the bacillus which we have described as a member of the large group of intestinal anaerobic bacteria which includes not only $B$. tetani, $B$. cedematis maligni, and $B$. aerogenes capsulatus, but also in all probability a large number of other as yet imperfectly differentiated varieties.

The microscopical and cultural characterictics appear to differ in important particulars from the already described members of the group. The microscopical appearances, indeed, closely resemble those of $B$. tetani, for the spore is round and absolutely terminal, and the possibility occurred to us that we might be dealing with atoxic strains of the tetanus bacillus. We are, however, at present inclined to the view that we are dealing with a distinct variety of bacillus, for not only did all four strains fail to produce toxin but their cultural characteristics on the media above described differed in essential details from those of $B$. tetani.

The injection of pure cultures failed to produce any effect in rabbits and guinea-pigs; a result which does not necessarily imply that this bacillus is incapable of taking part in the production of morbid changes in a septic wound. It is well known that pure cultures of $B$. cedematis maligni, $B$. tetani, and other members of the group may fail to produce any lesion after experimental inoculation. Investigations on this point are in progress, but the microscopical appearances of this bacillus so closely resemble those of $B$. tetani that we have thought it desirable to publish a short preliminary note. It is obvious that the occurrence of this bacillus in septic wounds adds considerably to the difficulty of diagnosis of tetanus by purely microscopical methods.

In conclusion, we desire to express our thanks to Professor Dean, under whose direction the investigations bave been carried out.

References.-Dean, H. R., and Mouat, T. B.: The Bacteria of Gangrenous Wounds, Journal of Royal Army Medical Corps, February and March, 1916.

Lingelsheim : Tetanus; in Kolle und Wassermann, Handbuch der pathogenen Mikroorgnnismen, se ond edition, 19,2 iv. Jen.

Macé, E.: Tra'łé pratiquere Bactériologie sixth edition, 1913, ii. Paris. Rohertson, Muriel: Notes upon Certain Anaerobes isolated from Wounds, Journ. of Path. and Bact., 1916, xx.

San Felice, F.: Untersuchungen über anaerobe Mikrnorganismen, Zeitschr. für Hygiene und Infecktionskrankheiten, 1893, xiv.

Tavel, E: Ueber den Pseudotetanusbaeillus des Darmes, Centralblatt frir Bakteriologie, 1898, xxiii.

\section{A CASE OF TETANUS TREATED BY INTRATHECAL AND INTRAMUSCULAR INJECTION OF ANTITOXIN.}

By JOHN GOW, M B MaNCH., F.R C.S. EvG., ASSISTANT RESIDENT SURGICAL OFFICER, MANCHESTER ROYAL INFIRMARX.

THE interesting features of the case here described are the success of the combined intrathecal and intramuscular injections and the use of the high dorsal injection, the arm being the prinsipal site of spasm

W. M., aged 32, was hit by shrapnel on Sept. 18th, 1916, receiving multiple superficial wounds on both hands and the left thigh. He was dressed at once, and a few hours later a piece of shrapnel was rernoved from his right hand. He does not remember receiving any prophylactic injection of antitetanio serum. $\mathrm{He}$ reached this hospital on Sept. 23rd, where his wounds were treated by saline fomentations and batbs. On Oct. 2nd, at 4 A.M., he noticed that his jaws were stiff so that he could not open his mouth, and an hour later he began to have violent and painful cramps in the right arm, in which he had not previously noticed any symptoms. Seen at 10 A.M. on that day his temperature was $99^{\circ} 6^{\circ} \mathrm{F}$. and his pulse 130 ; he was sweating profusely and had great pain in the right arm. The small superficial wound on the left thigh was granulating, but still discharging a little pus; the wounds of the left hand were dry and healing under scabs; on the right hand were multiple, small, superficial wounds, some bealing under scabs, some discharging a little pus. The right arm was flexed at the elbow and wrist, the fingers partially flexed at the metacarpo-phalangeal and extended at the interphalangeal joints. The flexor muscles of wrist and fingers were in a state of tonic contraction and violent spasms were occurring at intervals of about five minutes. The patient was holding the fingers of the right hand with his left to prevent flexion, and whenever he released them violent spasms occurred. The masseters were tense and the posterior neck muscles were stiff. The left arm was not stiff, but the triceps-jerk was exaggerated. Knee-jerks and plantar reflexes were exaggerated, especially on the right side.

At 1030 A.M., under anæsthesia, 5000 units of antitoxin were injected into the spinal theca in the lumbar region and 10,000 units were given intramuscularly. At 6 P.M. the patient was worse, the spasms occurring every two minutes. In view of the fact that the spasms were most marked in the muscles innervated by the nerve cells of the cervical enlargement, it was decided to inject the serum at a high level. Accordingly, on Oct. 3rd a needle was inserted between the first and second dorsal vertebræ; cerebro-spinal fluid was $w$ ithdrawn, ${ }^{1}$ and 4500 units of serum were injected. On Oct. 4th 5000 units were ivjected intramuscularly. On Oct. 5th the patient began to improve, and on this and two succeeding days 4500 units were given intramuscularly. On the 8th a generalised antitoxin rash developed and the patient seemed much worse; 4500 units were injected into the subarachnoid space between the first and second dorsal vertebrx. On the 9 th the patient was much better again and afterwards progressed well, the spasm very gradually passing off from the masseters and the arm muscles. On the 14 th 4500 units were injected intramuscularly.

The patient was discharged to convalescent hospital on Nov. 6th.

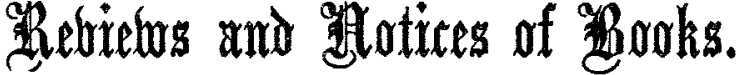

Makers of the XIXth Century: Herbert Spencer. By HuGH Elliot. London: Constable and Co., Limited. 1917. Pp. 330. Price 6s.

THIs is an excellent estimate of Herbert Spencer's lifework, made piquant by the personal attitude of the author towards that work. Mr. Eıliot says in his introductory chapter that it has been his fortune to read through the whole of spencer's works twice at an interval of 15 years, and each time during the progress of a great war. His first reading began when on active service in South Africa, when he found Spencer's doctrine of social freedom irresistibly attractive. During the progress of the present war he again read Spencer's furious declamation against warlike and military activities and found in many parts the arguments to be ill-founded, in other parts the conclusions to be false, while the style which formerly appeared to him so lucid now seemed hopelessly monotonous. Starting with this frank revelation of his estimate of Spencer as a guide and an informer, it is a great accomplishment on Mr. Elliot's part to make us see that though his views of Spencer, even in their most depreciatory sense, are just, yet his subject was none the less a powerful instrument for good in the civilisation of the world. No one can read this life of Herbert Spencer without feeling that the philosopher's central teachings concerning the evils of war and the dangers of military dictatorship were and are sound, and that although his social scheme was impracticable when he devised it, his arguments for its development are magnificently conceived and lucidly advanced. Much of his teaching has, indeed, passed into such common acceptance as to be disregarded as platitudes in modern discussions, and there are many writers and speakers to-day who rest their claims for this or that reform upon evidence which was marshalled originally by Spencer, and which in the course of half a century has become part and parcel of the general mental equipment. These things Mr. Elliot hrings out forcibly.

Herbert Spencer's life, though barren of interesting happenings in the ordinary sense of those words, was a far more singular one than that of many men of action or of

1 The cerebro-spinal fluid withrlawn from the dorsal region 24 hours after the injection of 5000 units into the lumbar region was found to contain antitoxin. Det ils of this observation are given in a paper on published in the pres of Tetanus, bv Professor 